\title{
A sereia amazônica dos Agassiz: zoologia e racismo na Viagem ao Brasil
}

Lorelai B. Kury

FIOCRUZ - UERJ

RESUMO

Louis e Elizabeth Agassiz viajaram pelo Brasil entre 1865 e 1866 . O relato publicado pelo casal e a repercussão da viagem indicam que o material produzido sobre o Brasil buscou atingir um público mais amplo do que o de leitores especialistas em história natural. A expedição pela Amazônia deu destaque à atividade científica de Agassiz e reforçou as estratégias de legitimação de suas teorias raciais e biogeográficas. Os problemas suscitados por sua viagem não são tratados como meramente locais. Os peixes do Amazonas e seus afluentes são utilizados para solidificar os argumentos dos criacionistas contra os evolucionistas, além de possibilitarem a defesa de uma biogeografia estática, onde cada ser teria sido designado para habitar uma região específica do planeta. Suas observações sobre a mestiçagem brasileira apóiam sua opinião de que as raças não devem se misturar, e fortalecem o campo político de parte da elite norte-americana que pregava a segregação dos negros. Palavras-chave: viajantes; biogeografia; mestiçagem.
ABSTRACT

Louis and Elizabeth Agassiz traveled to Brazil in 1865 and 1866. Their journal and the results of their journey indicate that they tried to reach much more than strict specialists in Natural History. This expedition in Amazon helps to spot Louis scientific activities and reinforce the strategy of legitimization of his racial and biogeographic theories. Questions raised during the journey were not considered as merely local ones. Fish from the Amazon Basin were treated as arguments to strengthen creationist camp against evolutionists. It also defends his static biogeography, which asserts that every being has been created to live in a specific region of the globe. Their observations about Brazilian miscegenation supported the idea that races mustn't hybridize, according to the part of North American elite that claimed for black segregation.

Key-words: travels; biogeography; miscegenation. 
O zoólogo suíço Louis Agassiz comandou uma expedição científica ao Brasil entre 1865 e 1866. Segundo ele, seu principal objetivo era pesquisar os peixes da Bacia Amazônica a fim de provar a falácia das teses evolucionistas. Nessa época, Louis Agassiz residia nos EUA, onde era considerado um grande naturalista, o mais legítimo sucessor de Humboldt. O sucesso do seu trabalho se deve à sua forte personalidade, à sua enorme capacidade de trabalho e competência, mas também ao fato de defender fervorosamente o criacionismo, numa época em que as teses darwinistas da seleção natural estavam se fortalecendo nos meios científicos. Extremamente preocupado em mostrar a natureza como obra do Criador, o zoólogo ligou-se, por intermédio de sua esposa norte-americana, a grupos unitarianistas, que admitiam releituras científicas da Bíblia, mas que evitavam o materialismo implícito no evolucionismo. ${ }^{1}$ Antes de sua viagem ao Brasil, Agassiz já tivera contato com peixes brasileiros, porque havia trabalhado com material deixado pelo zoólogo Johann Baptist von Spix, após sua morte. Como Martius e Spix, ele foi educado numa atmosfera impregnada pela Naturphilosophie e pelas obras científicas de Goethe. No entanto, as duas grandes referências científicas de Agassiz foram Alexander von Humboldt e Georges Cuvier. De Humboldt, Agassiz herdou a preocupação com a distribuição geográfica dos animais e o amor pelas viagens; de Cuvier, os métodos de trabalho da anatomia comparada e as crenças na fixidez das espécies e na teoria dos grandes cataclismos que revolucionaram o planeta.

\section{ENTRE O PITORESCO E O CIENTÍFICO}

O relato da viagem ao Brasil redigido pelo casal Agassiz, publicado pela primeira vez em 1867, pode ser analisado como uma proposta para o gênero da divulgação científica. Elizabeth Cary Agassiz encarregou-se de redigir a narrativa dos acontecimentos e peripécias que viveram, garantindo um tom pitoresco ao relato. Ela explicou de forma didática as teorias do naturalista e transcreveu cartas e trechos de conferências de seu marido. Louis acrescentou ao relato notas e apêndices que descreviam suas teorias científicas, aplicadas aos espécimes e fenômenos que estudou no Brasil.

O livro A Journey in Brazil ${ }^{2}$ é rico em detalhes sobre as paisagens, os costumes das populações e as instituições do país. Elizabeth, apesar das descrições pitorescas, não deixou de louvar e divulgar os trabalhos em ictiologia e geologia do infatigável esposo. Durante o tempo em que permaneceu no Brasil, um outro livro de divulgação científica, escrito por 
ela e seu enteado Alexander Agassiz, estava sendo lançado: Seaside Studies in Natural History, sobre os animais marinhos da Baía de Massachusetts. Quando da publicação do relato da viagem ao Brasil, um amigo do casal, em uma feliz comparação, escreveu em sua correspondência que o relato se assemelhava à sereia dos antigos poetas: é difícil dizer quando acaba a mulher e quando começa o peixe. Ele acrescentou: "a delicada observação da natureza do ponto de vista pitoresco suaviza o tom grave das observações e discussões científicas, da mais agradável maneira."3

Nos relatos da época ainda era rara a presença feminina em produções científicas. Por mais culta que fosse a viajante, o mais comum era que seus textos se enquadrassem no gênero do relato pitoresco ou das descrições artísticas, como foi o caso de Maria Graham e Marianne North. Os relatos de viagens científicas da primeira metade do século XIX, redigidos em sua quase totalidade por homens, não parecem, no entanto, separar pitoresco e científico, feminino e masculino. Ao contrário, eles buscam dar conta da compreensão dos fenômenos culturais, inserindo-os no mesmo sistema das explicações científicas. O texto dos Agassiz não apenas separa as observações culturais das explicações científicas, como parece considerar as primeiras menos sérias que as segundas. $\mathrm{O}$ pitoresco adquire o sentido de ameno e agradável; o científico é grave e difícil.

Já no início do século XIX os naturalistas haviam passado a separar os textos considerados puramente científicos das narrativas de viagem. Estas poderiam interessar um público culto mais amplo do que os especialistas em história natural. Mas, apesar dessa distinção, os relatos de viagem eram escritos pelos próprios naturalistas, e os detalhes sobre costumes e as descrições das paisagens faziam parte da própria compreensão do mundo e da natureza. A separação mulher/peixe presente em A Journey in Brazil indica que, por um lado, a especialização científica avançara em relação às décadas anteriores e, por outro lado, os resultados do trabalho de Agassiz prescindiam da viagem, ou seja, a viajante propriamente dita parece ser Elizabeth.

Sua presença no Brasil acrescentou prestígio a suas coleções e teorias, além de dar maior publicidade a seus resultados. $\mathrm{O}$ tom agradável no qual o relato foi escrito permitiu a difusão dos resultados a um público amplo. Agassiz não parecia contentar-se com a produção de dados e teorias. Queria falar a seu público sobre Deus e sobre a criação do mundo. Posteriormente, com a difusão avassaladora do evolucionismo, a ciência produzida em parte da Europa e da América vai distanciar-se das justificativas religiosas. A ciência passou a adotar um tom de neutralidade 
que exclui os assuntos religiosos, embora as grandes teorias biológicas e cosmológicas abordem implicitamente o problema da origem divina do mundo e de seus habitantes. O cenário norte-americano, em plena Guerra de Secessão, permitiu que a questão científica da distribuição geográfica dos peixes da Bacia Amazônica dissesse alguma coisa a respeito do futuro da humanidade e do lugar a ser ocupado pelos diferentes grupos humanos na Terra.

A cooperação que Louis Agassiz estabeleceu com sua mulher, Elizabeth, também permitiu a difusão de uma biogeografia estática e de considerações racistas em meio às elites brasileiras, de forma branda e moderna. Segundo Elizabeth, as lições ministradas por Agassiz no Rio de Janeiro, antes de partirem para a Amazônia, contaram, graças a ela, com a presença de mulheres, fato totalmente inusitado no Império de Pedro II. Em carta à sua família, Elizabeth acrescenta que a segunda aula de Agassiz fora ainda mais concorrida que a primeira, e que o imperador sancionara a presença de mulheres, levando consigo sua mulher e filha. ${ }^{4}$ A presença de Elizabeth reforçou a credibilidade e o papel de pretensa utilidade social dos trabalhos científicos de Agassiz.

\section{As Províncias zoOlÓgicas da AmazÔnia}

Desde o início de sua carreira, Agassiz buscava encontrar o plano de criação do mundo a partir das observações sobre a distribuição dos peixes nos mares e rios, inclusive os peixes fósseis. ${ }^{5} \mathrm{Um}$ grande problema para os não-evolucionistas da época era explicar porque os animais fósseis são diferentes dos atuais. Agassiz achava que os animais que povoaram a terra em diferentes épocas haviam sido destruídos por cataclismos. Deus teria recriado várias vezes os animais e plantas. Os animais que conhecemos hoje em dia teriam sido originados de uma criação recente.

Agassiz acreditava que todos os seres organizados foram criados para pertencer a uma determinada pátria, ou seja, existiria uma ligação essencial entre os seres e os lugares que habitam. As diferenças de clima não seriam suficientes para explicar a distribuição das espécies, já que em climas similares existem espécies diferentes. Os continentes e as grandes regiões do globo possuem faunas distintas. A lógica do povoamento do mundo saíra diretamente das mãos de Deus. No interior de cada região existiriam subdivisões que Agassiz chamou de províncias zoológicas, que se relacionam com as diferenças geográficas e de clima. Segundo ele, Deus teria criado novas espécies em diferentes épocas e designado a cada uma a sua pátria. A maior parte das espécies estaria estritamente limitada às 
suas províncias. Algumas espécies, no entanto, teriam uma vocação mais cosmopolita. Antes de sua fixação nos EUA, Agassiz pensava que a espécie humana era a única capaz de habitar toda a Terra. Mais tarde, começou a trabalhar com a hipótese de que as raças humanas constituíam espécies diferentes, criadas separadamente.

Para o naturalista, o plano de criação das espécies estabelecido por Deus determinava leis de organização da Terra. Cada região do planeta concentraria animais, plantas e paisagens que dependeriam uns dos outros, formando assim microcosmos com fisionomia própria. Mas, além destas particularidades, Deus, em suas criações sucessivas, estabeleceu um plano para o mundo. O naturalista poderia reencontrar esse plano divino se conseguisse agrupar os seres extintos e os atuais. Este agrupamento mostraria, segundo ele, uma gradação de complexidade ao longo do tempo. O estudo da embriologia dos animais atuais seria uma espécie de recapitulação de todos os animais que foram criados e extintos por Deus. No entanto, embora o agrupamento de animais atuais e fósseis formasse uma espécie de cadeia dos seres, Agassiz não acreditava que as espécies haviam se transformado, dando origem à fauna que conhecemos. Ao contrário, os animais seriam restritos não apenas a áreas geográficas específicas, mas também a épocas específicas. Quando uma determinada fauna é destruída por cataclismos, o Criador povoa o mundo novamente. A cadeia dos seres formada pelo plano da criação não caracteriza uma evolução das espécies no tempo.

Deste modo, a ordem do mundo é ao mesmo tempo universal e particular. A classificação baseada nos critérios da anatomia comparada dá conta do plano universal, abstrato. $\mathrm{O}$ estudo da distribuição geográfica das espécies explica, por sua vez, o pertencimento de cada ser à sua pátria de origem - onde Deus as fixou - e estabelece a época em que estas espécies viveram. Sua especialização no estudo de peixes e as pesquisas que fez ao longo de sua carreira científica indicam que o estudo das províncias zoológicas sempre se relacionou com a busca da lógica divina da criação. Em 1844, Agassiz já afirmava explicitamente:

Pode-se já considerar como provado que o embrião do peixe durante seu desenvolvimento, a classe dos peixes atuais nas suas numerosas famílias e o tipo de peixe em sua história planetária percorrem, sob todos os aspectos, fases análogas, através das quais segue-se sempre o mesmo pensamento criador, como um fio condutor que nos guia por toda parte na pesquisa do encadeamento dos seres organizados. ${ }^{6}$ 
As concepções de Agassiz diferiam radicalmente das teorias da evolução pela seleção natural defendidas por Darwin. O zoólogo suíço insistia em argumentar a partir da vontade do Criador e de sua constante intervenção no mundo. Para Darwin e os evolucionistas, a intervenção de Deus se limitaria ao sopro inicial da vida na Terra. Todas as espécies teriam uma única origem, não sendo, por conseguinte, frutos de criações repetidas e locais. O problema dos fósseis é essencial neste debate. Para Agassiz, eles não tinham nenhuma relação genética com os animais atuais. Para Darwin, os animais que conhecemos teriam se originado de ancestrais extintos.

O livro A Origem das espécies de Darwin foi publicado em 1859. No início da década de 1860, diversos naturalistas começavam a aderir ao evolucionismo darwinista. Mesmo que a adesão não tenha sido consensual, o problema da transformação das espécies estava na ordem do dia. Naturalistas adeptos do evolucionismo, nos moldes de Lamarck, também participaram dos debates. Para os contemporâneos, a diferença entre Lamarck e Darwin nem sempre era clara.

Agassiz, embora tivesse amplo reconhecimento intelectual por parte das autoridades norte-americanas e do grande público, começava a ser questionado por jovens naturalistas americanos, que rejeitavam suas interpretações, julgadas por demais teológicas, além de criticarem suas concepções racistas. Foi nesse contexto que surgiu para Agassiz a possibilidade de empreender uma expedição científica à Amazônia, espécie de Terra Prometida dos ictiólogos. Com a publicidade garantida por tal viagem, as observações geológicas e o material coletado nessa imensa região, o zoólogo acreditava poder obter fortes aliados para rebater as idéias evolucionistas e defender a fixidez das espécies e as criações sucessivas. Como o próprio Agassiz explicitou, o principal problema científico a ser elucidado pela expedição era o da origem das espécies. A expedição foi em grande parte financiada por um mecenas norte-americano. Outros naturalistas menos experientes, sua esposa Elizabeth, alunos voluntários, um desenhista (Burckhardt) e um fotógrafo (Hunnewell) acompanhavam o zoólogo suíço. As autoridades brasileiras e o próprio imperador deram amplo apoio à chamada expedição Thayer.

Na região amazônica, Agassiz dedicou-se a buscar provas de que houve uma recente glaciação na região (Pleistoceno), que teria marcado uma ruptura entre as espécies atuais e as extintas. O naturalista suíço já havia buscado provar que houve glaciações na Europa e nos Estados Unidos. Se conseguisse mostrar evidências de uma era glacial relativamente recente 
na Amazônia, Agassiz tornaria o fenômeno global, e não apenas localizado. Trabalhos de época (como os de Bates e Wallace) e atuais não compartilhavam essa opinião. O próprio Hartt, seu companheiro da expedição Thayer, se afastará paulatinamente da hipótese glaciária de Agassiz. Hoje em dia considera-se que o período de glaciação na região remonta a períodos muito anteriores, milhões de anos antes do que gostaria Agassiz.

Uma parte importante do relato de sua viagem foi dedicada à tentativa de mostrar evidências dessa glaciação, já que este fenômeno se relaciona com o objetivo central da viagem: o problema da origem das espécies. Agassiz não foi o único viajante no Brasil que buscou provar a teoria das criações sucessivas, de acordo com a linha proposta por Cuvier. Alcide d'Orbigny, discípulo de Cuvier, que esteve no Brasil, propôs um total de 27 criações sucessivas de faunas em todo o mundo.

Além de defender a extinção e a recriação de faunas, Agassiz defendia também que Deus havia criado “províncias zoológicas”. É interessante observar que os limites dessas províncias eram bastante estreitos. $\mathrm{O}$ vale amazônico continha várias províncias. Com relação aos peixes - seu principal objeto de estudo - Agassiz acreditava que as espécies encontradas variavam ao longo do Amazonas e eram diferentes para cada afluente do rio. Contrariamente a Darwin, ele achava que a variabilidade no interior de cada espécie era praticamente nula. Assim, o que hoje em dia um biólogo consideraria uma variedade, Agassiz tomava por uma espécie nova. Diversas passagens de seu relato de viagem confirmam sua busca pela extrema diferenciação de espécies. Em carta a um amigo, datada de agosto de 1865, entre Tajapuru e Gurupá, ele afirmava:

Parece evidente, em suma, e desde já, que a nossa viagem fará uma revolução na Ictiologia. Para começar, o jacundá de Tajapuru é diferente das espécies do Pará; da mesma forma o acará; temos depois uma espécie nova de sarapó e outra, também nova, de jeju, uma nova espécie de rabeca ${ }^{7}(.$.

Seguindo viagem (Tefé, setembro de 1865), as previsões de Agassiz se confirmam:

Já cheguei à certeza de que é mister distinguir várias faunas ictiológicas muito nitidamente caracterizadas; assim, as espécies que habitam o Rio Pará, do litoral marítimo até a foz do Tocantins, diferem das que se encontram na rede de anostomoses que unem o Rio Pará ao Amazonas propriamente dito. As espécies da Amazonas, acima do Xingu, diferem das do curso inferior do Tapajós ${ }^{8}(. .$. 
Os resultados científicos da viagem de Agassiz foram divulgados em alguns artigos e no relato de viagem escrito por ele e por sua esposa. Ele e seus companheiros coletaram por volta de oito mil objetos de história natural. O desenhista Burkhardt fez centenas de aquarelas, sobretudo de peixes. O material zoológico da expedição Thayer pertence atualmente ao Museu de Zoologia Comparada da Universidade de Harvard.

\section{MESTIÇAGEM E RAÇA PURA}

A imagem da sereia - mistura de gente e peixe - sintetiza também os interesses que norteiam o casal em sua viagem pelos rios e cidades do Brasil, principalmente da Amazônia. Em dezembro de 1865, Elizabeth Agassiz faz a seguinte avaliação dos resultados, ainda parciais, da expedição:

As seis semanas que acabamos de passar foram muito proveitosas do ponto de vista científico. Não só Agassiz aumentou seus conhecimentos sobre os peixes, como teve ocasião de acumular uma soma de fatos novos e interessantes sobre as numerosas variedades produzidas pelo cruzamento de índios, pretos e brancos, e pode juntar às suas notas uma série bem completa de fotografias.?

Assim, a Amazônia foi palco de coletas para a zoologia criacionista de Agassiz, mas também funcionou como contra-exemplo cultural e racial e ser evitado pela América do Norte. À enorme quantidade de material zoológico recolhido pelos viajantes devem ser acrescentados os dois álbuns fotográficos, conservados na biblioteca do Museu de Zoologia Comparada da Universidade de Harvard até 1935, quando foram transferidos para o Arquivo Fotográfico do Peabody Museum da mesma universidade. ${ }^{10}$ Além disso, o relato de viagem é repleto de observações sobre a mestiçagem brasileira e inclui gravuras que ilustram "tipos" brasileiros, principalmente de Manaus. Agassiz acrescentou no apêndice o pequeno texto "Permanência dos traços característicos nas diferentes raças humanas", onde dá conta dos resultados de suas observações antropológicas.

No início de sua carreira, Agassiz acreditava que todos os seres humanos constituíam uma única espécie, mesmo que houvesse uma hierarquia de perfeição entre as diferentes raças. Quando ainda estava na Suíça, havia escrito:

Enquanto os animais são de espécies distintas nas diferentes províncias zoológicas às quais pertencem, o homem, apesar da diversidade das raças, constitui uma única e mesma espécie sobre toda a superfície do globo. Sob este 
aspecto, dentre tantos outros, o homem aparece como um ser excepcional para a criação, da qual ele é o objetivo e o fim último. ${ }^{11}$

Vinte anos mais tarde, quando viajava pela Amazônia, o zoólogo tomou notas como a seguinte:

Por mim, julgo estar demonstrado que, a não ser que se prove que as diferenças existentes entre as raças índia, negra e branca são instáveis e passageiras, não se pode, sem estar em desacordo com os fatos, afirmar a comunidade de origem para todas as variedades da família humana. ${ }^{12}$

É provável que sua transferência para os Estados Unidos, em 1846, seja uma espécie de divisor de águas quanto às suas crenças sobre a unidade da espécie humana. O contato com os negros norte-americanos e com os teóricos racistas locais fez com que Agassiz adote a crença na poligenia das espécies humanas. Ou seja, passou acreditar que as raças humanas não se originaram de um ascendente comum; foram fruto de criações distintas. Como o fez para os peixes, Deus havia criado as raças para habitarem regiões específicas. As migrações humanas confundiram esse quadro.

O mais importante representante da etnologia poligenista norte-americana foi Samuel Morton, que havia publicado Crania Americana, em 1839, e Crania Aegyptiaca, em 1844. Assim que chegou aos Estados Unidos, Agassiz visitou a famosa coleção de crânios de Morton. Em 1850 o naturalista suíço publicou três artigos no Christian Examiner, de Boston, onde defende, ao mesmo tempo, o abolicionismo e a poligenia. Segundo ele, a existência de raças humanas criadas separadamente não contradiria a Bíblia, já que esta se referia apenas aos caucasianos. Já em 1854 o naturalista estava plenamente integrado à comunidade científica norte-americana, de credo poligenista, pois assinou a introdução do importante livro Types of Mankind, de Josiah Nott e George Gliddon.

Stephen Jay Gould divulgou diversos trechos da correspondência de Agassiz que tinham sido suprimidos por sua mulher quando da publicação de uma biografia do autor em $1885^{13}$. Em carta à sua mãe, em 1846, ele relatou a impressão do primeiro contato com negros:

Foi em Filadélfia que estive pela primeira vez em contato prolongado com os negros; todos os empregados de meu hotel eram homens de cor. Mal posso lhe expressar a dolorosa impressão que experimentei, particularmente porque a sensação que eles me inspiram vai contra todas nossas idéias a respeito da confraternização de todos os tipos de homem e da origem única 
de nossa espécie. Mas a verdade deve estar acima de tudo. Não obstante, senti piedade à vista dessa raça degradada e degenerada, e tive compaixão pelo seu destino ao pensar que se tratava realmente de homens. Contudo, é-me impossível reprimir a impressão de que eles não são feitos do mesmo sangue que nós. ${ }^{14}$

Alguns anos mais tarde, em carta escrita a um amigo em plena Guerra Civil americana, afirmou: "Temos que lutar já contra a influência da igualdade universal a fim de não impedir nosso progresso," ${ }^{15}$ referindo-se à inserção dos negros na sociedade, com o fim da escravidão. Quando os Agassiz vieram ao Brasil, este tipo de idéia estava totalmente consolidada para ambos. Seu contato com as populações locais, apesar de afável, foi marcado por esse sentimento de tranqüila superioridade. Elizabeth, por exemplo, descreveu um casal de índios mundurucu, que os acompanhou de Maués a Manaus, como se buscasse distinguir neles algum traço humano:

Poder-se-ia crer que as tatuagens desses índios fariam necessariamente desaparecer todo traço de beleza física. Isto não se dá com o casal que temos diante de nós. Os traços são finos, o arcabouço é sólido e firme, mas não pesado, e no seu porte há mesmo uma dignidade passiva que se nota apesar da tatuagem. Não conheço nada mais calmo que a fisionomia do homem; não é uma estupidez obtusa, pois o olhar é observador e denota sagacidade, mas conserva uma expressão de tranqüilidade tal que não se pode imaginar que tenha ou possa ter alguma vez outra diferente. ${ }^{16}$

Uma das maiores preocupações de Louis Agassiz com relação às raças que considerava inferiores era a possibilidade da mestiçagem. Durante sua estadia na Amazônia, pôde observar diversos cruzamentos raciais que nunca tinha visto antes. As observações eram facilitadas, segundo ele, pelo fato de grande parte do que chama de população inculta andar seminua. O casal Agassiz ficou bastante impressionado com as possibilidades existentes para os estudos raciais na Amazônia. Elizabeth afirmou:

Em nenhuma outra parte do mundo se poderia estudar tão completamente como no Amazonas a mistura de tipos, pois aí os mamelucos, os cafuzos, os mulatos, os caboclos, os negros e os brancos produziram, por suas alianças, uma confusão que à primeira vista parece impossível destrinchar. ${ }^{17}$

O método usado por Agassiz para destrinchar esse emaranhado é o que chamou de "método da história natural". Segundo ele, como o objetivo de sua viagem era o estudo dos peixes e das glaciações, não podia 
proceder como os antropólogos da época, que praticavam sobretudo uma antropologia física comparada. Desse modo, ele diz: "não pude empreender sobre as raças humanas as observações muito cuidadosas, baseadas em medidas minuciosas e repetidas mil vezes, que caracterizam os recentes trabalhos dos antropólogos". ${ }^{18}$ Efetivamente, o zoólogo conhecia de perto o trabalho de antropólogos norte-americanos, como Morton e Nott. Apesar de não ser especialista em antropometria, as observações sobre a mestiçagem do Brasil ocuparam lugar importante no relato e no dia-adia de expedição. Elizabeth conta que uma das peças da casa em que estavam hospedados em Manaus serviu de ateliê fotográfico:

Agassiz passa ali a metade dos dias, em companhia de Hunnewell, que, tendo consagrado todo o tempo de sua estada no Rio a aprender os processos fotográficos, adquiriu certa habilidade na arte da "semelhança garantida". O grande obstáculo, porém, são os preconceitos populares. Entre os índios e negros reina a superstição de que um retrato absorve alguma coisa da vitalidade do indivíduo nele representado e que está em grande perigo de morte próxima quem se deixa retratar. ${ }^{19}$

Em interessante artigo, G. Isaac descreve e analisa as fotos tiradas por Agassiz e sua equipe no Brasil. O naturalista usou a chave de classificação dos termos lingüísticos do Brasil para a definição das diferentes raças e cruzamentos, como preto, branco, mulato, cafuzo, caboclo e mameluco. Em momento algum tornam-se claros os critérios que usa para definir tipos puros e tipos mestiços. Isaac lembra que tanto Elizabeth quanto o estudante de medicina e membro da expedição William James - irmão do escritor Henry James e futuro psicólogo de renome - comentam inúmeras vezes a dificuldade de distinguir as misturas raciais que vêem.

As fotos produzidas são bastante chocantes pela forma como foram produzidas e pelo arranjo posterior que sofreram. Grande parte dos homens fotografados está nua. Algumas mulheres posaram nuas e outras desnudaram apenas os seios. James comenta com ironia as cenas que presenciou no ateliê fotográfico de Agassiz:

Ao entrar no quarto, encontrei o Professor ocupado no convencimento de três Mocas, as quais ele chamava de índias puras, mas que, penso eu, pareciam ter sangue branco. Elas estavam graciosamente vestidas em musselina branca, enfeitadas com jóias, tinham flores nos cabelos e exalavam um excelente cheiro de pripioca. Aparentemente refinadas, em nada desavergonhadas, consentiram que tomassem as máximas liberdades para com elas e 
duas, sem muito problema, foram induzidas a tirar a roupa e posarem nuas. Enquanto eu estava lá, o Sr. Tavares Bastos entrou e perguntou-me jocosamente se eu era muito ligado ao Bureau de Antropologia. ${ }^{20}$

Os álbuns fotográficos conservados nos arquivos norte-americanos mostram um outro traço característico dos estudos raciais da época. Para comparar as raças, Agassiz não recorreu a fotografias de brancas, muito menos despidas. Ele acrescentou a seu álbum 3 retratos (cartões estereoscópicos) de estátuas clássicas, que funcionaram como espécie de modelos com os quais as imagens dos nativos brasileiros deveriam ser comparadas. Isaac lembra ainda que, em seu apêndice do livro A Journey in Brazil, Agassiz descreveu detalhadamente os seios de mulheres índias e negras e omitiu qualquer descrição dos seios de mulheres brancas, provavelmente para não chocar o público leitor da obra, classificável como literatura de viagem e não obra estritamente científica.

As poses de seus modelos revelam a preocupação em mostrar, em alguns casos, tomadas do corpo inteiro de frente, costas e perfil. Os retratos de pessoas sentadas expõem claramente uma das mãos do fotografado, com um dos braços pousado sobre as pernas. Este tipo de foto ajusta-se às preocupações gerais da antropologia física da época e deveria funcionar como prova para as afirmações de Agassiz sobre as raças que encontrou no Brasil, como a seguinte:

O que à primeira vista logo me impressionou ao ver índios e negros reunidos foi a diferença marcada que há nas proporções relativas das diferentes partes do corpo. Como os macacos de braços compridos, os negros são em geral esguios; têm pernas compridas e tronco relativamente curto. Os índios, ao contrário, têm as pernas e braços curtos e o corpo longo; sua conformação geral é mais atarracada. Prosseguindo na minha comparação direi que o porte do negro lembra os Hilobatas esguios e irrequietos, ao passo que o índio tem algo do orango inativo, lento e pesado. ${ }^{21}$

A experiência com fotografias raciais não era nova para Agassiz. Em 1850, na Carolina do Sul, com a ajuda de um daguerreotipista, Agassiz havia tirado uma série de fotografias de escravos. Brian Wallis, em interessante análise dessa documentação ${ }^{22}$, diz que as fotos dividiam-se em duas séries. A primeira representaria uma abordagem preocupada com a forma do corpo e a proporção dos membros, onde os modelos posaram totalmente nus, de frente, costas e perfil. Uma segunda série retrata os escravos da cintura para cima, mesmo as mulheres com o busto desnudo. Este tipo de imagem permitiria uma análise mais pormenorizada da for- 
ma da cabeça e de detalhes de expressão. O método de trabalho de Agassiz é o de um zoólogo: compara pessoas de diferentes "raças" como se comparasse exemplares de diferentes espécies animais. Segundo ele: "O fato de diferirem por traços constantes e permanentes basta, por si, para justificar uma comparação entre as raças humanas e as espécies animais.” ${ }^{23}$

Desse modo, o naturalista pode avaliar de forma negativa o que chama de hibridações. $\mathrm{O}$ indivíduo resultante do cruzamento de diferentes raças perde as melhores características das raças puras. Segundo Agassiz,

o resultado de ininterruptas alianças entre mestiços é uma classe de pessoas em que o tipo puro desapareceu, e com ele todas as boas qualidades físicas e morais das raças primitivas, deixando em seu lugar bastardos tão repulsivos quanto os cães amastinados, que causam horror aos animais de sua própria espécie, entre os quais não se descobre um único que haja conservado a inteligência, a nobreza, a afetividade natural que fazem do cão de pura raça o companheiro e o animal predileto do homem civilizado. ${ }^{24}$

Agassiz e sua mulher parecem um tanto chocados não apenas com a mestiçagem propriamente dita, mas também com a aceitação pela sociedade de pessoas de todas as cores. Durante sua estadia em Manaus, o casal teve a oportunidade de ir a um baile, oferecido em homenagem a Tavares Bastos. Elizabeth faz o seguinte comentário quanto aos participantes da festa:

Era grande a variedade de toaletes; sedas e cetins roçavam-se com lãs e musselinas, e os rostos mostravam todas as tonalidades, do negro ao branco, sem contar as cores acobreadas dos índios e dos mestiços. Não há aqui, com efeito, o menor preconceito de raça. Uma mulher preta - admitindo-se, já se vê, que seja livre - é tratada com tanta consideração e obtém tanta atenção quanto uma branca. ${ }^{25}$

Ainda no Rio de Janeiro, Elizabeth escrevera à sua família, constatando que "não há aqui o sentimento de inferioridade do preto que existe entre nós." ${ }^{26}$ Esta suposta democracia racial observada pelos Agassiz seria prejudicial no sentido de que a mestiçagem produz uma população fraca e depauperada, composta por seres "vagos, sem caráter nem expressão". Segundo Elizabeth, "o fato, tão honroso para o Brasil, de ter o negro pleno e inteiro acesso a todos os privilégios do cidadão tende a aumentar, antes que a diminuir, sua importância numérica." ${ }^{27}$

O problema racial foi detectado em diversos momentos ao longo do relato da viagem. Segundo os autores, um dos grandes desafios da re- 
gião do Amazonas era aumentar sua população. O problema tornava-se mais grave do ponto de vista da civilização da região, pois os brancos que aí se estabeleceram viram-se reduzidos a adotar a moralidade e os costumes das ditas raças inferiores. A região apresentava, nas palavras de Agassiz, "o singular fenômeno de uma raça superior recebendo o cunho de uma raça inferior, de uma classe civilizada adotando os hábitos e rebaixando-se ao nível dos selvagens" ${ }^{28}$ A aristocracia branca, apesar de explorar os índios, adota seus hábitos e, como eles, senta-se no chão e come com as mãos. Comparando os brancos do Brasil aos norte-americanos e aos ingleses, afirmou que se os dois últimos sujam suas mãos com tráfico de escravos e exploração da mão-de-obra indígena, nunca, entretanto, "quereriam degradar ao nível dos índios, como o fazem os portugueses; não se abaixariam a adotar-lhes os costumes." ${ }^{29}$ A solução para a civilização do Amazonas seria o incentivo à imigração de uma classe "mais moralizada".

Assim, a expedição de Louis Agassiz ao Brasil pode ser compreendida como uma ocasião que o naturalista encontrou para dar maior visibilidade às suas teorias raciais e biológicas sobre a origem das espécies. Os problemas suscitados por sua viagem não foram tratados como meramente locais. Os peixes do Amazonas e seus afluentes foram utilizados para solidificar os argumentos dos criacionistas contra os evolucionistas, além de possibilitarem a defesa de uma biogeografia estática, onde cada ser teria sido designado para habitar uma região específica do planeta. Sua observações sobre a mestiçagem brasileira apóiam sua opinião de que as raças não devem se misturar, e fortalecem o campo político de parte da elite norte-americana que pregava a segregação dos negros. Ele diz, explicitamente: "Aqueles que põem em dúvida os efeitos perniciosos da mistura de raças e são levados por falsa filantropia, a romper todas as barreiras colocadas entre elas, deveriam vir ao Brasil." ${ }^{30}$

\section{CONCLUSÃO}

A abordagem que Agassiz empreendeu dos fenômenos étnicos harmoniza-se com suas concepções biogeográficas. Para a ciência da época, as explicações sobre as origens da humanidade deveriam incluir reflexões quanto à distribuição das espécies animais e vegetais sobre o planeta. Como resumiu um contemporâneo de Agassiz ${ }^{31}$, aceitar o monogenismo requer algum tipo de explicação evolucionista, já que os descendentes do primeiro casal humano espalharam-se pelo mundo e deram origem a povos muito diversos. A passagem do branco ao negro, por exemplo, ou do 
ortognata ao prognata seria, então, obra dos séculos e da influência climática. O mesmo autor afirma que os poligenistas encontram dificuldades em explicar a adaptabilidade de certos povos a condições de vida e lugares muito distintos.

Agassiz procede de maneira a incorporar as divisões geográficas à hierarquia de perfeição entre os seres vivos. Se com relação aos peixes as províncias zoológicas são respeitadas, no que diz respeito aos seres humanos, a mistura de "raças" criadas para habitarem regiões específicas mostravase prejudicial. De modo a evitar que os "brancos" fossem julgados como as demais "raças" e não devessem atuar fora de sua "províncias zoológicas", como é o caso dos colonizadores da América, o naturalista considerou-os como os únicos capazes de ultrapassar as barreiras geográficas impostas pelo Criador a todos os demais seres. $\mathrm{O}$ traço distintivo dos brancos não seria, segundo ele, apenas físico. É pelos traços morais que se distinguem os homens. É a moralidade que aproxima o homem de Deus e lhe confere direitos sobre o resto da criação. Enfim, o Deus de Agassiz havia feito uma escolha pelos brancos. Os demais seres estavam condenados a existências locais; ao homem branco coube o mundo inteiro.

\section{NOTAS}

${ }^{1}$ Sobre a vida e as concepções científicas de Louis Agassiz, ver: LURIE, Edward. Louis Agassiz: a life in science. Chicago: The University of Chicago Press, 1960, e WINSOR, Mary P. Reading the shape of nature: comparative zoology at the Agassiz Museum. Chicago: The University of Chicago Press, 1991.

${ }^{2}$ AGASSIZ, Elizabeth Cary e Louis. A Journey in Brasil. Boston: Fields \& Osgood, 1867. Utilizo aqui a edição brasileira: Viagem ao Brasil, Belo Horizonte: Itatiaia; São Paulo: EDUSP, 1975.

${ }^{3}$ Carta de Elizabeth a Sarah e Emma Cary (Cambridge, janeiro de 1868), transcrita em PATON, Lucy Allen. Elizabeth Cary Agassiz. A Biography, Boston: Houghton Mifflin Co.; New York: The Riverside Press, 1919, pp. 107-108.

${ }^{4}$ Cartas datadas de 10 e 12 de junho de1865, em ibid., pp. 82-84.

${ }^{5}$ Cf. AGASSIZ, Louis. Notice sur la géographie des animaux. Neuchatel: H. Wolfrath, agosto, 1845 (separata da Revue Suisse).

${ }^{6}$ AGASSIZ, Louis. Monographie des poissons fossiles du Vieux Grès Rouge ou système dévonien (Old Red Sanndstone) des Iles britanniques et de Russie. Neuchatel: Soleure, 1844, p. XXVI.

${ }^{7}$ Viagem ao Brasil, op. cit., p. 110.

${ }^{8}$ Ibid., pp. 140-141.

${ }^{9}$ Ibid., p. 182. 
${ }^{10}$ Cf. ISAAC, Gwyniera, “Louis Agassiz's Photographs in Brazil. Separate Creations”. History of Photography, 21(1), 1997, pp. 3- 11.

${ }^{11}$ AGASSIZ, Louis. Notice..., op. cit., p. 31.

${ }^{12}$ Viagem ao Brasil, op. cit., pp. 183-184.

${ }^{13}$ Agassiz, Elizabeth Cary. Louis Agassiz: his life and correspondence. Boston: Houghton Mifflin, 1885 .

${ }^{14}$ Apud GOULD, Stephen J. A Falsa medida do homem. São Paulo: Martins Fontes, 1991, pp. 32-33.

${ }^{15}$ Ibid., p. 37.

${ }^{16}$ Viagem..., op. cit., p. 196.

${ }^{17}$ Ibid., p. 182.

${ }^{18}$ Ibid., p. 305.

${ }^{19}$ Ibid., p. 171.

${ }^{20}$ Apud ISAAC, op. cit., p. 6.

${ }^{21}$ Viagem..., op. cit., p. 305.

${ }^{22}$ WALLIS, Brian, “Black bodies, White Science. Louis Agassiz's Slave Daguerreotypes”, American Art, 9(2), 1995.

${ }^{23}$ Viagem..., op. cit., p. 183.

$172 \quad{ }^{24}$ Ibid., p. 184.

${ }^{25} \mathrm{Ibid}$., p. 174.

${ }^{26}$ Carta a Sarah Cary (Rio de Janeiro, 16 de maio de 1865), transcrito em PATON, op. cit., p. 80.

${ }^{27}$ Viagem..., op. cit., p. 180.

${ }^{281}$ bid., p. 154.

${ }^{29}$ Ibid., loc. cit.

${ }^{30}$ Ibid., p. 180.

${ }^{31}$ BERTILLON, Louis A. “Acclimatement, acclimatation”, em R. DELORME e A. DECHAMBRE (editores). Dictionnaire Encyclopédique des Sciences Médicales. Paris: P. Ascelin, de Lage, Victor Masson et Fils, 1864.

Artigo recebido em 09/2000. Aprovado em 03/2001. 